\title{
Expression Characteristics and Clinical Significance of HMGB1 in Gastric Cancer: A Meta - Analysis
}

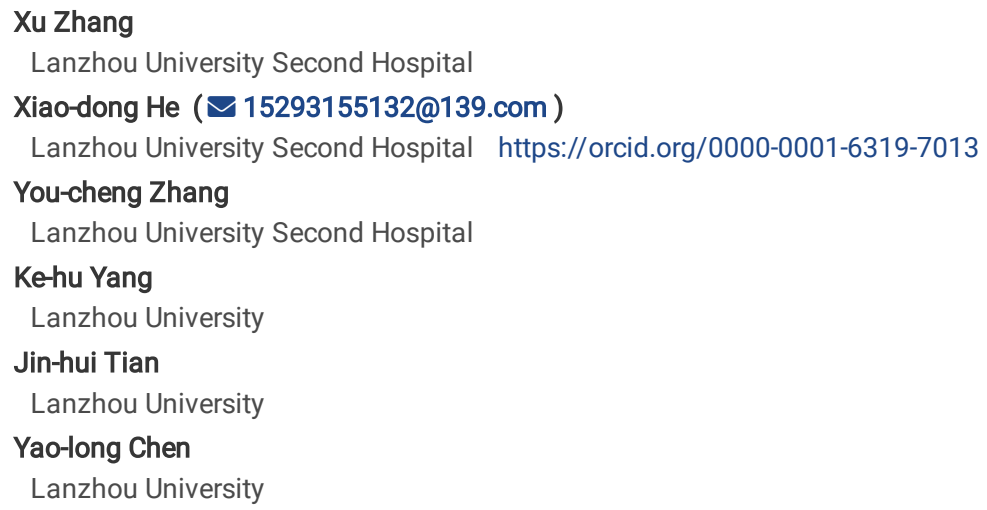

Research Article

Keywords: HMGB1 protein, stomach neoplasms, neoplasm metastasis, cell differentiation, Meta - analysis

Posted Date: May 24th, 2021

DOl: https://doi.org/10.21203/rs.3.rs-481817/v1

License: (c) (i) This work is licensed under a Creative Commons Attribution 4.0 International License. Read Full License 


\title{
Abstract
}

Objective: To clarify the expression of HMGB1 and its relationship with clinical features of gastric cancer.

Methods: Multiple databases were systematically searched for relevant studies from 1997 to 2021 . We screened case - control studies stating that the association between HMGB1 protein expression and clinical characteristics in gastric cancer.

Results: In total, eight independent studies with 872 patients were included. Meta - analysis indicated higher odds of HMGB1 being present in gastric tumor tissues compared to para - tumor controls $₫ \mathrm{OR} \otimes 4.15,95 \rrbracket \mathrm{Cl}(3.09,5.58), \mathrm{P} \otimes 0.01 \rrbracket$. High HMGB1 expression was also associated with poor differentiation rate

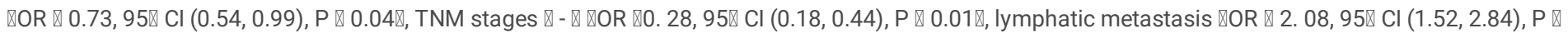
$0.01 \rrbracket$ and diffuse type of Lauren classification [OR $\otimes 0.57,95 \otimes \mathrm{Cl}(0.38,0.84), \mathrm{P} \otimes 0.01 \rrbracket$. However, there was no significant correlation between HMGB1 expression between gender and age.

Conclusion: Our results illustrated that HMGB1 protein was strongly associated with adverse clinicopathological features of gastric cancer. HMGB1 may be a promising target in the development of gastric cancer.

\section{Introduction}

Gastric cancer is the fifth most prevalent malignant tumor in the world, and the prognosis is often poor because gastroscopic examination is not widely available. Inadequate access to gastroscopy, patients are already in the middle and late stages of the disease when they are seen for signs and symptoms, and often have a poor prognosis ${ }^{[1]}$. In recent years, markers and targets related to the diagnosis and treatment of gastric cancer have received a lot of attention $^{[2]}$. High mobility group protein B1 (HMGB1) is considered to be a cellular factor form of immunomodulator, which plays a strong role in regulating autophagic flux in cellular stress. HMGB1 is a damage-related submodule involved in the development of carcinogenesis and is a potential tumor biomarker ${ }^{[3]}$. Researchers have found that HMGB1 is overexpressed in gastric malignant tumor tissues ${ }^{[4]}$, but there is a correlation between HMGB1 expression and the pathological features of gastric cancer, due to the relatively small sample size and the varying quality of the designs. The statistical relationship between the two studies is unclear due to the relatively small number of samples and the varying quality of the designs. In this study, we collected literature on HMGB1 expression in gastric cancer tissues from 199 to 2021, and we combined the data to investigate the association between HMGB1 expression in tumor tissues and postoperative pathological data.

\section{Materials And Methods}

\author{
Literature Review Strategy
}

By reviewing the literature on the correlation between HMGB1 protein and postoperative pathological data of gastric cancer published in the database from 1997 to 2021. Foreign language databases: PubMed, Embase, Web of science; the search method is ("Stomach Neoplasms" or "Gastric Neoplasms" or "Cancer Neoplasms" or "Gastric Neoplasms" or "Cancer of Stomach" or "Stomach Cancers" or "Gastric Cancers". " Gastric Cancers ") and ("HMGB1 protein" or "HMG1" or "FM1 Gene Product" or "Amphoterin" or "HMGB1" or "HMG 1 Protein" or "Heparin Binding Protein p30"). Chinese databases: China Knowledge Base, Wan Fang, Vipshop, and China Biomedical Literature. Chinese Biomedical Literature Database (CBLD). The Chinese database was searched by ("gastric Gastric cancer" or "gastric malignant tumor" and ("HMGB1 protein" or "high migration rate"). (HMGB1 protein" or "HMGB1"). The terms "HMGB1 protein" and "HMGB1 protein" were used in PubMed MeSH, China. Chinese Biomedical Literature Database subject headings and keywords list to select the corresponding search terms.

Inclusion and Exclusion Criteria

Inclusion Criteria

(1) Retrospective studies or case-control studies of HMGB1 and gastric cancer; (2) Definite diagnosis of gastric cancer with detailed clinical data and postoperative pathological findings, scientific study design, and control groups in the study; (3) Data with immunohistochemical stained pathological slides.

\section{Exclusion Criteria}

(1) Only cellular or animal experiments were involved; (2) Meeting abstracts and reviews; (3) Studies exploring the expression of HMGB1 outside of gastric cancer tissues (e.g., serum, plasma); (4) Preoperative radiotherapy and other treatments; (5) Duplication of literature and serious data deficiencies; (6) Incomplete or limited data of enrolled cases.

Literature Screening and Data Extraction

The literature was screened by more than two researchers according to the search strategy and inclusion exclusion criteria, and relevant information (first author, time of publication), basic clinical information (sex, age) and pathological information (metastasis of lymph nodes, TNM stage, tumor differentiation, Lauren typing) were extracted.

Literature Quality Assessment

The Newcastle-Ottawa Scale (NOS), a non-competitive study scale, was used as the evaluation criterion for this study ${ }^{[5]}$. The NOS consists of eight items divided into three sections, including study subjects, group comparability, and results of study type (cohort study) or exposure (case-control study). For each 
item, a series of corresponding options are provided. A scoring system is used to provide a semi-quantitative assessment of study quality. The NOS scores range from 0 to 9 .

Statistical Methods

Data consolidation and analysis were performed by RevMan 5.3 and STATA16 software. The heterogeneity between studies is determined by $\mathrm{I}^{2}$ test ${ }^{[6]}$, when $\mathrm{P}$ $\geq 0$. 1 and $\mathrm{I}^{2} \llbracket 50 \%$, the heterogeneity effect is small, and the fixed-effect model is suitable; When $\mathrm{P} \llbracket 0.1$ or $\mathrm{I}^{2} \geq 50 \%$, the heterogeneity effect between studies is large, and the random-effect model is more accurate. For $\mathrm{P}<0.1$ or $\mathrm{I}^{2} \geq 50 \%$, the heterogeneity between studies is large, and the random-effect model is more accurate. Sensitivity analysis with STATA software explores the impact of each study on the final statistical results. The funnel plot shows the development bias. The test level of $a=0.05$ was used to determine the bias. The odds ratio (OR) and $95 \% \mathrm{Cl}$ were used for the Morin diagram at a test level of $a=0.05$.

\section{Results}

Literature Inclusion and Exclusion Results

Four hundred and nineteen relevant papers were retrieved, and the final eight papers were included according to the previously established criteria, of which two studies were published in English journals and six in Chinese journals (Fig. 1).

Literature Features and Quality Assessment

After reading the whole paper, a quality assessment was performed by NOS. The main reason for the low score of the paper by YUAN HB et al ${ }^{[7]}$ is that the study by YUANHB et al ${ }^{[7]}$ did not give a detailed description of the origin of the normal group, and it was not possible to distinguish between normal and paracancerous tissues of the volunteers. It was not possible to distinguish between the normal gastric mucosa and the paracancerous tissues of the patients. The characteristics and NOS scores of the included literature are shown in Table 1.

Table 1

Basic characteristics and NOS quality score of literature

\begin{tabular}{|c|c|c|c|c|c|c|c|c|c|c|c|c|c|c|c|}
\hline \multirow[t]{2}{*}{ Author } & \multirow{2}{*}{$\begin{array}{l}\text { Published } \\
\text { (year) }\end{array}$} & \multirow{2}{*}{$\begin{array}{l}\text { Tumor } \\
\text { tissues }\end{array}$} & \multirow{2}{*}{$\begin{array}{l}\text { Adjacent } \\
\text { tissues }\end{array}$} & \multicolumn{2}{|c|}{ Gender } & \multicolumn{2}{|c|}{ Age(years) } & \multicolumn{2}{|c|}{$\begin{array}{l}\text { Lauren } \\
\text { classification }\end{array}$} & \multicolumn{2}{|c|}{$\begin{array}{l}\text { TNM } \\
\text { stage }\end{array}$} & \multicolumn{2}{|l|}{ Grade } & \multicolumn{2}{|c|}{$\begin{array}{l}\text { Lymph node } \\
\text { metastasis }\end{array}$} \\
\hline & & & & Male & Female & $\frac{5}{60}$ & $>60$ & Intestinal & Diffuse & 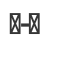 & $\mathbb{X - X}$ & $\begin{array}{l}\text { Well- } \\
\text { Moderate }\end{array}$ & Poor & Negative & Posi' \\
\hline $\begin{array}{l}\text { YUAN } \\
\mathrm{HB}^{[7]}\end{array}$ & 2012 & 51 & 30 & 36 & 15 & - & - & 43 & 8 & 28 & 23 & 32 & 19 & 40 & 11 \\
\hline $\mathrm{Bao}^{[8]}$ & 2010 & 78 & 78 & 55 & 23 & 44 & 34 & - & - & 35 & 43 & 38 & 40 & 34 & 44 \\
\hline $\begin{array}{l}\text { GUO } \\
\text { YD }\end{array}$ & 2014 & 240 & 40 & 167 & 73 & 134 & 106 & 80 & 160 & 219 & 21 & 104 & 136 & 111 & 129 \\
\hline $\begin{array}{l}\text { KONG } \\
Z Y^{[10]}\end{array}$ & 2017 & 52 & 21 & 39 & 13 & 24 & 28 & - & - & 10 & 42 & 43 & 9 & 19 & 33 \\
\hline LI RL ${ }^{[11]}$ & 2015 & 32 & 32 & 20 & 12 & - & - & - & - & 23 & 9 & - & - & 5 & 27 \\
\hline LIU J ${ }^{[12]}$ & 2017 & 230 & 230 & 121 & 109 & 127 & 103 & 75 & 115 & 209 & 21 & 102 & 128 & 106 & 124 \\
\hline$W U Z^{[13]}$ & 2017 & 104 & 104 & 76 & 28 & 44 & 60 & - & - & - & - & 34 & 70 & 27 & 77 \\
\hline Suren $^{[14]}$ & 2018 & 85 & - & 51 & 34 & - & - & - & - & 48 & 37 & 36 & 49 & 30 & 55 \\
\hline
\end{tabular}

Note: “-” indicates a lack of data.

Meta-Analysis Results

Expression of HMGB1 in Gastric Cancer and Paraneoplastic Tissues

A total of 6 studies $^{[8-13]}$ were performed, 736 cases met the inclusion criteria, and corresponding control groups were established. A total of 505 paraneoplastic gastric mucosal tissues were enrolled and analyzed with RevMan software with acceptable heterogeneity $\left(P=0.10, I^{2}=46 \%\right)$. The results indicated that HMGB1 was overexpressed in gastric cancer tissues (Fig. 2A).

Relationship between HMGB1 Expression and Gender and Age in Gastric Cancer Tissues

The 6 articles included in the group contained gender information ${ }^{[8-13]}$. The ratio of male to female cases was $478 / 258$. There is no heterogeneity among the studies $\left(P=0.14, I^{2}=40 \%\right)$. Meta analysis showed: $O R=0.90,95 \% \mathrm{Cl}(0.65,1.25), Z=0.62, P=0.54$, it can be considered that the expression of $\mathrm{HMGB} 1$ has no significant difference between male and female gastric cancer patients ( Fig. 2B). There are 5 articles ${ }^{[8-10,12-13]}$ covering the expression of HMGB1 in gastric cancer tissues of patients of different ages. There were 373 cases under 60 years old, and 331 cases older than 60 years old. There is no heterogeneity between the studies $\left(P=0.41, I^{2}=0 \%\right)$, analysis shows: $O R=0.84,95 \% \mathrm{Cl}(0.62,1.15), Z=1.09, P=0.28$, it can be considered that the expression of $\mathrm{HMGB} 1$ has no difference in gastric cancer patients of different age groups (Fig. 2C). 
Correlation between the Degree of Differentiation of Gastric Cancer Tissues and the Level of HMGB1 Protein Expression

In the included 7 related articles ${ }^{[7-10,12-14]}$, there are 389 cases of high- and middle-differentiated gastric cancer tissues, and 451 cases of low-differentiated gastric cancer tissues. The heterogeneity among the research data is small $\left(P=0.30, I^{2}=17 \%\right)$, using fixed effects model analysis: $O R=0.73,95 \% \mathrm{Cl}(0.54$, $0.99), Z=2.03, P=0.04$. It shows that the gastric cancer tissue with high expression of HMGB1 has a lower degree of differentiation (Fig. 2D).

Expression of HMGB1 in Gastric Cancer Tissues with Different TNM Stages

A total of 7 papers $^{[7-12,14]}$ were included in the analysis, of which 572 patients were in stage I-II and 196 in stage III-IV, with little heterogeneity among the data $\left(P=0.12, I^{2}=40 \%\right)$. The results of the analysis: $O R=0.28,95 \% \mathrm{Cl}(0.18,0.44), Z=5.39, P<0.01$. It can be concluded that the differences in the expression of HMGB1 in different TNM stages are statistically significant, and the expression of HMGB1 in stage III-IV tumor tissues is statistically significant. The expression of HMGB1 was higher in stage III-IV tumors than in stage I-II tumors (Fig. 2E).

Relationship between Lymph Node Metastasis and HMGB1 Expression

Seven articles ${ }^{[7-13]}$ were enrolled in the group, and the ratio of the number of patients with lymph node metastasis to those without metastasis was $445 / 342$. The heterogeneity between the groups is small $\left(P=0.14, I^{2}=38 \%\right)$, the analysis results, $O R=2.08,95 \% \mathrm{Cl}(1.52,2.84), Z=4.60, P<0.01$, it can be considered that HMGB1 is highly expressed in gastric tumor tissue of patients with lymph node metastasis (Fig. 2F).

Expression of HMGB1 in Gastric Cancer Tissues of Different Lauren Classifications

A total of 3 studies $^{[7,9,12]}$ were included in the analysis, including 198 cases of midgut type, 283 cases of diffuse type, and no mixed cases. RevMan 5.3 software analysis results showed no heterogeneity $\left(P=0.27, \mathrm{I}^{2}=23 \%\right)$, Meta analysis results: $\mathrm{OR}=0.57,95 \% \mathrm{Cl}(0.38,0.84), \mathrm{Z}=2.82, \mathrm{P}<0.01$, it can be considered that HMGB1 is highly expressed in gastric cancer tissues classified as diffuse by Lauren, and the difference is statistically significant (Fig. 2G).

Sensitivity Analysis

In order to check the interference of each research on the final results, the STATA software was used for parameter mapping (Fig. 3), which showed that the results are reliable.

Issuance Bias Detection

As shown in Fig. 4 (A-G), it can be seen from the symmetry of the graph that the research included is less likely to be biased in publication.

\section{Discussion}

The global incidence of gastric cancer is about $5.7 \%$, and the incidence in China is about $31.21 \%{ }^{[15-16]}$, and its mortality rate is about $8.2 \%$, ranking third among global malignant tumors ${ }^{[1]}$. Although the diagnosis and treatment of gastric cancer have made rapid progress in recent years, the 5 -year survival rate of advanced gastric cancer is still less than $25 \%{ }^{[17]}$. At present, the survival and prognosis of patients with gastric cancer are still considered to be related to the staging of tumors, but because patients in the same stage still have obvious prognostic differences ${ }^{[18]}$, we are looking for a broad focus on the occurrence and development of gastric cancer.

During the development of tumors, activated immune cells release HMGB1 to the outside of the cell, through the late-stage glycosylation end product receptor (RAGE) and Toll. Related pathways such as receptor-like receptors activate downstream pathways, regulate inflammatory immune responses, and are related to tumor proliferation and metastasis, cell metabolism and apoptosis, and autophagy pathways ${ }^{[3,19]}$. Studies have shown that HMGB1 protein is involved in non-small cell lung cancer ${ }^{[20]}$, Glioma ${ }^{[21]}$, colorectal cancer ${ }^{[22]}$, pancreatic cancer ${ }^{[23]}$, liver cancer ${ }^{[24]}$, ovarian tumors ${ }^{[25]}$ and other tumors have a certain degree of high expression ${ }^{[26-27]}$. We found that This phenomenon can also be confirmed in gastric cancer. Meta analysis showed that, compared with the adjacent tissues, the expression of HMGB1 protein in gastric cancer tissues was up-regulated. Researchers found that the HMGB1 rs1045411 genotype is significantly correlated with clinical factors such as Lauren typing, differentiation, clinical staging, and auxiliary chemotherapy ${ }^{[28]}$. This study confirms that HMGB1 is more highly expressed than other types of tissues in the Lauren type of diffuse type. In addition, studies have found that HMGB1 promotes cell migration and participates in tumor cell migration mainly by regulating cell adhesion and modifying the extracellular matrix ${ }^{[3]}$. HMGB1 can also induce melanophore activity inhibitory protein by activating the nuclear factor KB pathway, and combine with fibronectin and integrin to promote the invasion and migration of tumor cells ${ }^{[29-30]}$. In in vivo experiments, the use of HMGB1/RAGE axis inhibitor can reduce the growth and metastasis ability of tumors ${ }^{[31]}$. This study proved that HMGB1 in the tissues of gastric cancer patients with TNM stages $\mathbb{\varangle} \rrbracket$ and with lymph node metastasis also showed characteristics that have been expressed, which also further proves that HMGB1 is associated with the degree of invasion of gastric cancer.

In addition, the present study found that gastric cancer tissues with high expression of HMGB1 protein were less differentiated. This result was also confirmed in other types of tumor studies, such as breast cancer ${ }^{[32]}$, bladder cancer ${ }^{[3]}$, ovarian cancer ${ }^{[34]}$, kidney cancer ${ }^{[35]}$, colorectal cancer ${ }^{[36]}$, where HMGB1 ${ }^{2}$ was over- $^{2}$ expressed in the tumor tissues with low differentiation. The HMGB1 was overexpressed in hypofractionated tumor tissues. It has been shown that HMGB1 may cause recurrence of tumor after radiotherapy by activating the TLR2 / YAP / HIF-1a signal pathway and inducing the dedifferentiation of neighboring CD133-pancreatic cancer cells ${ }^{[37]}$. 
There are some limitations in this study: first, the number of included studies and patients is small, and the number of included subgroup analyses for different clinical pathological factors is insufficient, which affects the accuracy of the conclusions. The inclusion of this study is limited to the published literature, and the lack of gray data may lead to the omission of negative results. Secondly, due to the lack of original source data, the current analysis is based on single factor study without adjustment for different risk factors, which may lead to confounding bias.

\section{Conclusion}

In summary, HMGB1 protein is overexpressed in gastric malignant tumor tissues, and the level of HMGB1 expression may correlate with TNM stage, lymph node metastasis, degree of differentiation, and Lauren typing. We believe that HMGB1 plays an important role in the disease progression and tumor metastasis of gastric cancer. Due to the limitations of the included literature and sample size, these results and conclusions need to be further verified by more high-quality, large-sample, multi-center studies.

\section{Declarations}

Acknowledgements: We are grateful to Mr. He Xiaodong and Mr. Zhang Youcheng of the Second Hospital of Lanzhou University for their support in data management, and to Mr. Yang Kehu, Mr. Tian Jinhui and Mr. Chen Yaolong of the Evidence-based Centre of the School of Basic Medicine of Lanzhou University for their support in statistical data.

Author Contributions: All authors made substantial contributions to conception and design, acquisition of data, or analysis and interpretation of data; took part in drafting the article or revising it critically for important intellectual content; gave final approval of the version to be published; and agree to be accountable for all aspects of the work.

\section{Compliance with ethical standards}

Conflict of interest: The authors declare that they have no conflict of interest. The present study was conducted following the Helsinki Declaration of the World Medical Association. All participants have given consent for publication.

Funding: This research received no specific funding/grant from any funding agency in the public, commercial, or not-for-profit sectors.

Ethics approval and consent: Not applicable.

Consent for publication: Not applicable.

An availability of data and materials: All data generated or analysed during this study are included in this published article.

\section{References}

1. FERLAY BRAYF, SOERJOMATARAM J. I, et al. Global cancer statistics 2018: GLOBOCAN estimates of incidence and mortality worldwide for 36 cancers in 185 countries [J]. CA Cancer J Clin. 2018;68(6):394-424.

2. WANG SUNT, PING D. Y, et al. Integrated profiling identifies SLC5A6 and MFAP2 as novel diagnostic and prognostic biomarkers in gastric cancer patients [J]. Int J Oncol. 2020;56(2):460-9.

3. ROWE SIMSGP, RIETDIJK DC. ST, et al. HMGB1 and RAGE in inflammation and cancer [J]. Annu Rev Immunol. 2010;28:367-88.

4. KONO AKAIKEH, SUGAI K. H, et al. Expression of high mobility group box chromosomal protein-1 (HMGB-1) in gastric cancer [J]. Anticancer Res. 2007;27(1a):449-57.

5. STANG A. Critical evaluation of the Newcastle-Ottawa scale for the assessment of the quality of nonrandomized studies in meta-analyses [J]. Eur $\mathrm{J}$ Epidemiol, 2010, 25 (9): 603-605.

6. HIGGINS JP, THOMPSON SG, DEEKS JJ, et al. Measuring inconsistency in meta-analyses [J]. BMJ. 2003;327(7414):557-60.

7. WANG YUANHB, CHEN DX. XQ, et al. Expression and clinical significance of high mobility group box 1 in gastric cancer and precancerous lesions [J]. Chin J Digest Med Imageol (Electronic Edition). 2012;2(6):376-9.

8. QIAO BAOG, ZHAO Q. H, et al. Prognostic value of HMGB1 over-expression in resectable gastric adenocarcinomas [J]. World J Surg Oncol. $2010 ; 8: 52$.

9. BAI GUOYD. GH. Expression of HMGB1 and RAGE protein in gastric carcinomas tissue associated with their clinicopathological parameter [J]. Chin J Cancer Prev Treat. 2014;21(9):684-7, 691.

10. WANG KONGZY, SUN HP. MJ, et al. Expression and clinical significance of HMGB1 in gastric cancer [J]. Chin J Cancer Prev Treat. 2017;24(21):1513-7.

11. LI RL, QU FL, LI QC, et al. Expression of HMGB1 in gastric cancer tissues and gastric cancer cell lines [J]. Progress in Modern Biomedicine. 2015;15(16):3065-8.

12. JI LIUJ, BI ZG. CR, et al. Expression and clinical significance of HMGB1 and RAGE protein in gastric cancer tissues [J]. Chin J Clin Onclo Rehabil. 2017;24(10):1197-200.

13. OUYANG WUZ. XH, SU XL. Expression of HMGB1 in gastric cancer and its relationship with clinical pathological characteristics [J]. Chin Med Herald. 2017;14(8):9-11, 28.

14. ARDA GOKAY A SUREND. SAYINER A. High Mobility Group Box 1 (HMGB1) expression in gastric adenocarcinomas [J]. J Buon. 2018;23(2):422-7. 
15. SOERJOMATARAM FERLAYJ, DIKSHIT I. R, et al. Cancer incidence and mortality worldwide: Sources, methods and major patterns in GLOBOCAN 2012 [J]. Int J Cancer. 2015;136(5):E359-86.

16. ZHENG CHENW, ZENG R H, et al. Annual report on status of cancer in China, 2011 [J]. Chin J Cancer Res, 2015,27 (1): 2-12.

17. LABIANCA CATALANOV, BERETTA R. GD, et al. Gastric cancer [J]. Critical Reviews in Oncology / Hematology. 2005;54(3):209-41.

18. O'MORAIN MILNEAN,CARNEIROF. C, et al. Nature meets nurture: Molecular genetics of gastric cancer [J]. Hum Genet. 2009;126(5):615-28.

19. ZHANG KANGR, ZEH Q. HJ, et al. HMGB1 in cancer: Good, bad, or both [J]. Clin Cancer Res. 2013;19(15):4046-57.

20. XU XIAQ, CHEN J. H, et al. Association between an elevated level of HMGB1 and non-small-cell lung cancer: A meta-analysis and literature review [J]. Onco Targets Ther. 2016;9:3917-23.

21. SEIDU RA, WU M, SU Z, et al. Paradoxical role of high mobility group box 1 in glioma: A suppressor or a promoter [J]. Oncol Rev. 2017;11(1):325.

22. CHENG KJ, ALSHAWSH MA, MEJIA MOHAMED EH, et al. HMGB1: an overview of its versatile roles in the pathogenesis of colorectal cancer [J]. Cell Oncol (Dordr). 2020;43(2):177-93.

23. CEBRIAN MJ, BAUDEN M, ANDERSSON R, et al. Paradoxical role of HMGB1 in pancreatic cancer: Tumor suppressor or tumor promoter [J]. Anticancer Res. 2016;36(9):4381-9.

24. HUEBENER HERNANDEZC, PRADERE P. JP, et al. HMGB1 links chronic liver injury to progenitor responses and hepatocarcinogenesis [J]. J Clin Investig. 2018;128(6):2436-51.

25. ZHAO JULL. CY, YE KF, et al. Expression and clinical implication of Beclin1, HMGB1, p62, survivin, BRCA1 and ERCC1 in epithelial ovarian tumor tissues [J]. Eur Rev Med Pharmacol Sci. 2016;20(10):1993-2003.

26. BROWN CK ELLERMANJE, DE VERA M, et al. Masquerader: High mobility group box-1 and cancer [J]. Clin Cancer Res. 2007;13(10):2836-48.

27. CHUNG HW, LEE SG, KIM H, et al. Serum high mobility group box-1 (HMGB1) is closely associated with the clinical and pathologic features of gastric cancer [J]. Journal of Translational Medicine. 2009;7:38.

28. QU BAOG. F, HE L, et al. Prognostic significance of Tag SNP rs1045411 in HMGB1 of the aggressive gastric cancer in a chinese population [J]. PloS One. 2016;11(4):e0154378.

29. POSER I, GOLOB M, BUETTNER R, et al. Upregulation of HMG1 leads to melanoma inhibitory activity expression in malignant melanoma cells and contributes to their malignancy phenotype [J]. Mol Cell Biol. 2003;23(8):2991-8.

30. SASAHIRA T, KIRITA T, OUE N, et al. High mobility group box-1-inducible melanoma inhibitory activity is associated with nodal metastasis and lymphangiogenesis in oral squamous cell carcinoma [J]. Cancer Sci. 2008;99(9):1806-12.

31. BLOOD TAGUCHIA, DEL TORO G DC, et al. Blockade of RAGE-amphoterin signalling suppresses tumour growth and metastases [J]. Nature. 2000;405(6784):354-60.

32. ZHANG SUNS, CUI W. Z, et al. High mobility group box-1 and its clinical value in breast cancer [J]. Onco Targets Ther. 2015;8:413-9.

33. YANG GL, ZHANG LH, BO JJ, et al. Increased expression of HMGB1 is associated with poor prognosis in human bladder cancer [J]. J Surg Oncol. 2012;106(1):57-61.

34. QU JIANGC. X, KE H, et al. Association between the HMGB1 / TLR4 signaling pathway and the clinicopathological features of ovarian cancer [J]. Mol Med Rep. 2018;18(3):3093-8.

35. WANG QIEGQ, CHU CT. YF, et al. Expression of HMGB1 / RAGE protein in renal carcinoma and its clinical significance [J]. International Journal of Clinical Experimental Pathology. 2015;8(6):6262-8.

36. ZHANG X, YU J, LI M, et al. The association of HMGB1 expression with clinicopathological significance and prognosis in Asian patients with colorectal carcinoma: a meta-analysis and literature review [J]. OncoTargets Therapy. 2016;9:4901-11.

37. SHI ZHANGL, CHEN H. H, et al. Dedifferentiation process driven by radiotherapy-induced HMGB1 / TLR2 / YAP / HIF-1alpha signaling enhances pancreatic cancer stemness [J]. Cell Death Dis. 2019;10(10):724.

\section{Figures}




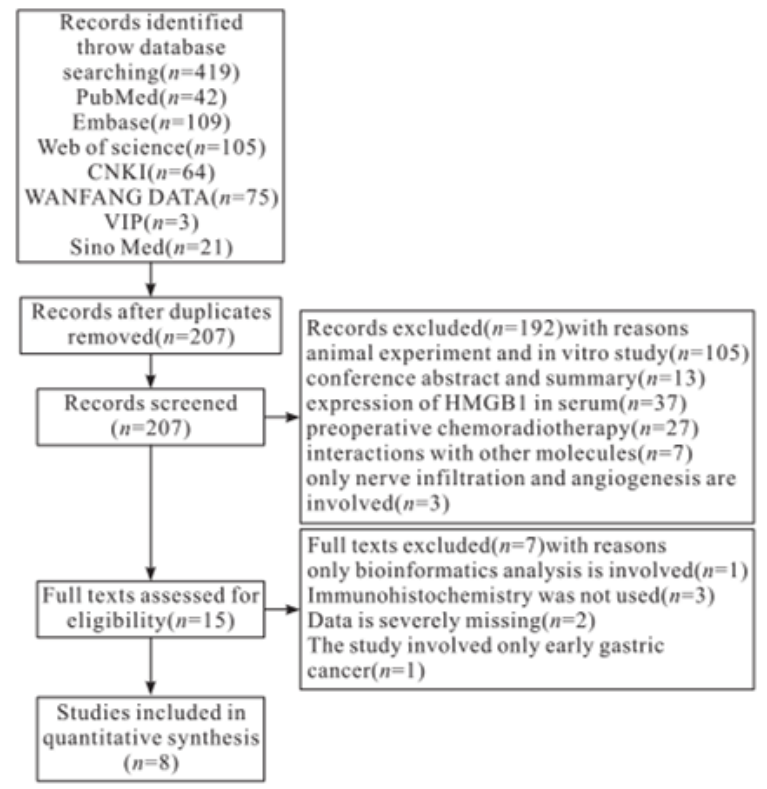

Figure 1

Literature screening and flow chat

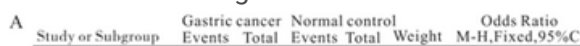

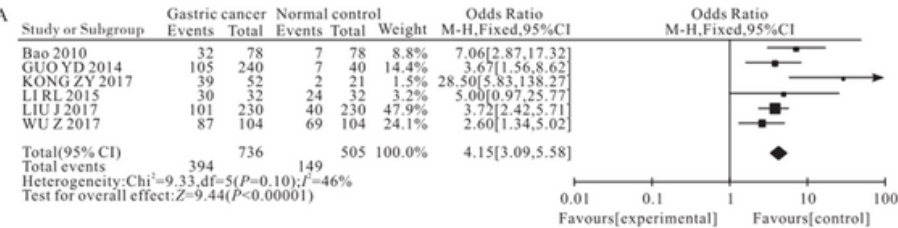

D

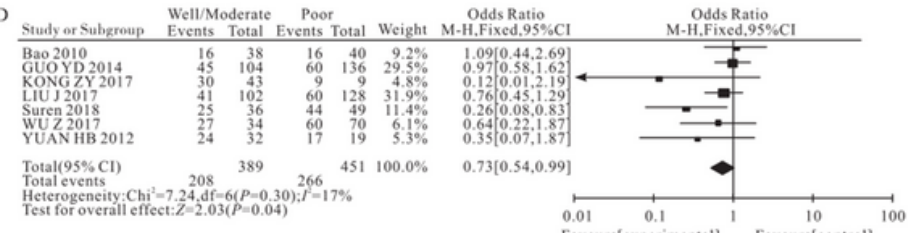

B

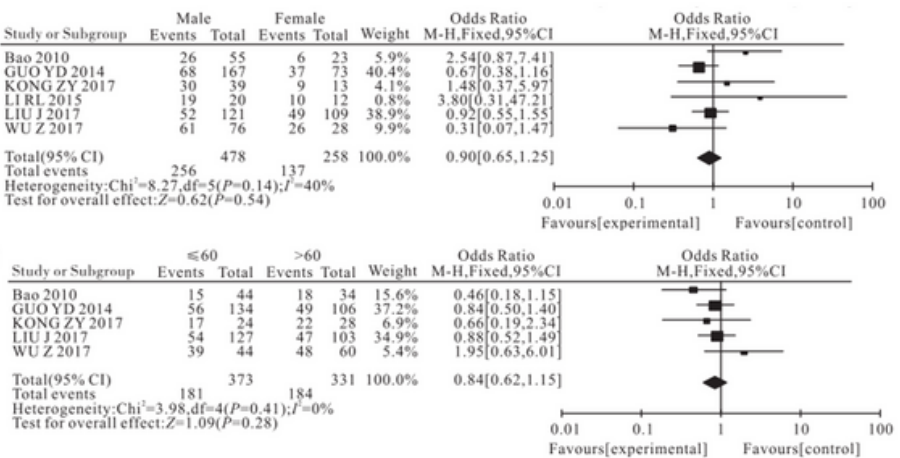

E

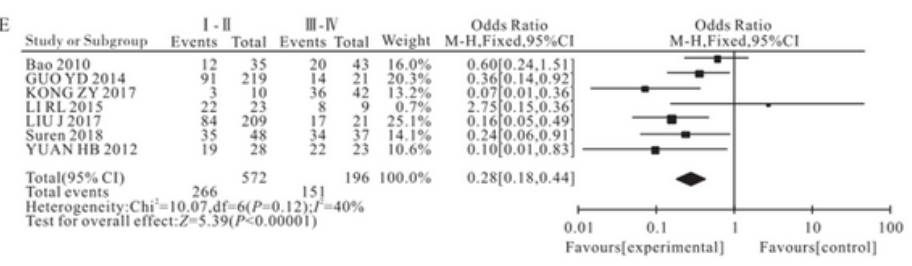

Lymph node non-Lymph

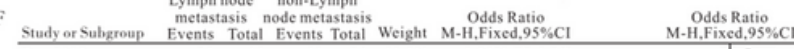

Bao 2010 (2014

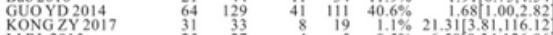

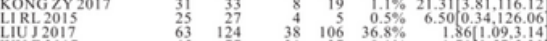
$\begin{array}{lrrrrrr}\text { WUT } 2017 & 63 & 124 & 38 & 106 & 36.8 \% & 1.86 \\ \text { WUZ } 2017.09 .3 .14 \\ \text { YUANHB } 2012 & 11 & 11 & 21 & 27 & 8.1 \% & 1.710 .57 .20 \\ \end{array}$ $\begin{array}{lllll}\text { Total }(95 \% \mathrm{Cl}) & 445 & 342 & 100.0 \% & 2.08[1.52,2.84]\end{array}$

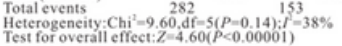
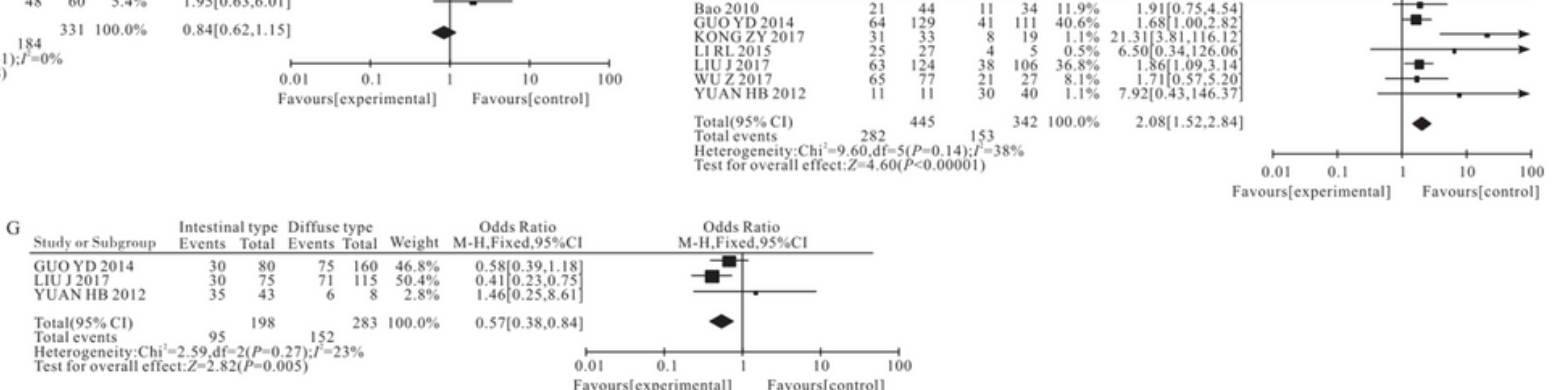

Figure 2

Meta - analysis of relationship between HMGB1 expression and clinicopathological features of gastric cancer A HMGB1 expression in gastric cancer and adjacent tissues B HMGB1 expression in gastric cancer patients of different gender C HMGB1 expression in gastric cancer patients of different age D HMGB1 expression in gastric cancer with different differentiation E HMGB1 expression in gastric cancer with different TNM stages $F$ HMGB1 expression in gastric cancer with and without lymph node metastasis G HMGB1 expression in gastric cancer with different Lauren classification 

Meta-analysis estimates,
given named study is omitted

' Lower CI Limit o Estimate' Upper CI Limit

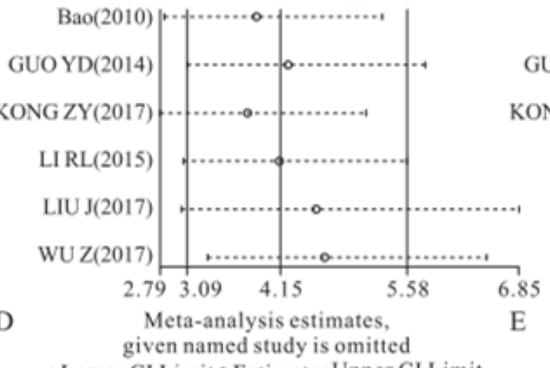

given named study is omitte

' Lower CI Limit ० Estimate ' Upper CI Limit

$\mathrm{Bao}(2010)$

GUO YD(2014)

KONGZY(2017)

LIU J(2017)

Sirem(2018)

WU Z(2017)

YUAN HB(2012)

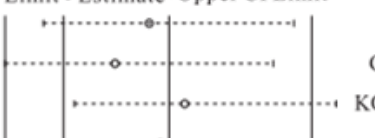

B

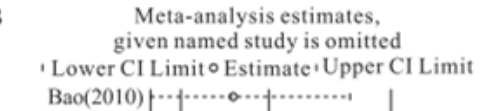

Meta-analysis estimates,
given named study is omitted

Lower Crimito Estimater Upper Crimit

C

C Meta-analysis estimates, given named study is omitted given named study is omitted
' Lower CI Limit o Estimate' Upper CI Limit

GUO YD(2014)

KONG ZY(2017)

LI RL(2015)

LIU J(2017)

WU Z(2017)

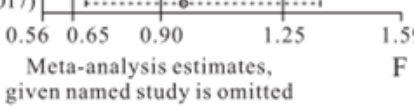

given named study is omitted

' Lower CI Limit $\circ$ Estimate 'Upper CI Limit

$\operatorname{Bao}(2010)$

GUO YD(2014)

KONG ZY(2017)

LIRL(2015)

LIU J(2017)

Sirem(2018)

YUAN HB(2012)

$\begin{array}{lllll}0.44 & 0.54 & 0.73 & 0.99 & 1.08\end{array}$

$\begin{array}{lllll}0.13 & 0.18 & 0.28 & 0.44 & 0.53\end{array}$

59

F

Meta-analysis estimates.

given named study is omitted

- Lower CI Limit • Estimate 'Upper CI Limit

Bao(2010)

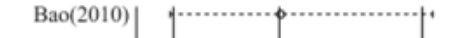

Figure 3

Sensitivity analysis of the relationship between HMGB1 expression and clinical pathological parameters A HMGB1 expression in gastric cancer and adjacent tissues B HMGB1 expression in gastric cancer patients of different gender C HMGB1 expression in gastric cancer patients of different age D HMGB1 expression in gastric cancer with different differentiation E HMGB1 expression in gastric cancer with different TNM stages F HMGB1 expression in gastric cancer with and without lymph node metastasis

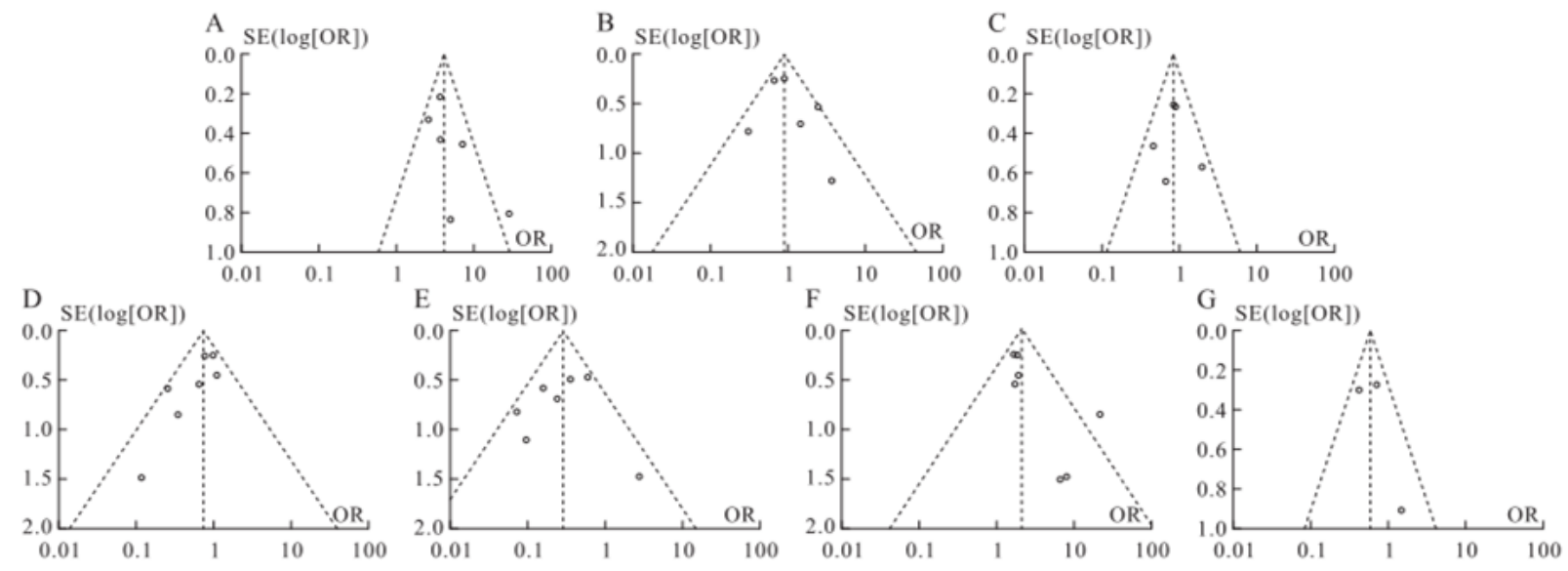

Figure 4

Funnel plot of the relationship between HMGB1 expression and clinical pathological parameters A HMGB1 expression in gastric cancer and adjacent tissues B HMGB1 expression in gastric cancer patients of different gender C HMGB1 expression in gastric cancer patients of different age D HMGB1 expression in gastric cancer with different differentiation E HMGB1 expression in gastric cancer with different TNM stages F HMGB1 expression in gastric cancer with and without lymph node metastasis G HMGB1 expression in gastric cancer with different Lauren classification 